\title{
Uncertainties in Techniques used to Determine Areas under Irrigation in the Upper Orange River Basin
}

\section{Mahasa Pululu $\mathbf{S}^{1 *}$, Palamuleni Lobina $\mathbf{G}^{2}$ and Ruhiiga Tabukeli $\mathbf{M}^{2}$}

${ }^{1}$ Department of Geography, Faculty of Natural and Agricultural Sciences, Qwaqwa Campus, University of the Free State, Phuthaditjhaba, South Africa ${ }^{2}$ Department of Geography and Environmental Sciences, School of Environmental and Health Sciences, Mafikeng Campus, North West University, Mmabatho, South Africa

\begin{abstract}
The paper addresses uncertainties that emanate as a result of methods used to determine irrigation areas in the Upper Orange River catchment area. The largest water user is the irrigation sector. What is not known for all schemes are the return flows but an average estimation of $13 \%$ is done for the main irrigation areas. Though several previous studies have addressed water conservation and demand management in the in the Orange-Senqu River catchment area; some pitfalls/caveats remain identified by these studies pertaining to the practical implementation of results. It was the necessary to look into several methods used since the results produced, in some instances differed so much.

An establishment of a standard methodology for the collection of data on irrigation water applied to crops, water use by crops and crop yields is a necessity. Establishment of an inventory GIS Database for irrigation inventory could prove useful if it could enhance the collation and collection of detailed and reliable data about irrigation water use by crops and crop yields. It could lead to documenting best management practices for irrigation in the catchment area. Another path could be to assess and consider various instruments that could be used for water conservation and demand management and further made improvements on water conservation and water demand management (WC/WDM) in the sector.
\end{abstract}

Keywords: Satellite imagery; Climate change; Crop water requirements; Geographic information systems (GIS); Remote sensing (RS)

\section{Introduction}

This chapter provides the characteristics of the study area and describes the methodology employed to determine areas under irrigation in the study area. It concludes by showing inherent uncertainties in each method used to determine the size and allocation of irrigation water for that particular area.

\section{Characteristics of the Upper Orange-Senqu River Basin}

Geographical overview: The Upper Orange WMA covers 103671 $\mathrm{km}^{2}$ and is part of the Orange River watercourse. Lesotho has been included in the study area and covers $30492 \mathrm{~km}^{2}$. The total area is 134 $163 \mathrm{~km}^{2}$ as shown in Figure 1. This area lies between Latitudes $\left(28^{\circ} 0^{\prime} 0^{\prime \prime}\right.$ and $\left.32^{\circ} 0^{\prime} 0^{\prime \prime} \mathrm{S}\right)$ and Longitudes $\left(24^{\circ} 0^{\prime} 0^{\prime \prime}\right.$ and $\left.30^{\circ} 0^{\prime} 0^{\prime \prime} \mathrm{E}\right)$. The Orange River, (called the Senqu River in Lesotho), originates in Lesotho Maluti Mountains, close to the Lesotho's highest peak, Thabana Ntlenyana at $3.482 \mathrm{~m}$ above sea level. If there were no developments of any nature in the river basin, the average natural run-off would be more than 12000 million $\mathrm{m}^{3} / \mathrm{a}$, representing the average river flow that would be evidenced. It now happens that less than half of the natural runoff reaches the river mouth at Alexander Bay due to high levels of developments in the basin [1].

The Upper Orange WMA falls within the Orange River basin which is the largest river basin in South Africa. The Modder-Riet River catchment which is geographically part of the Lower Vaal catchment is included in the Upper Orange WMA because the water resources of the Modder-Riet are augmented by numerous transfers from the Orange River and its catchments. The rest of the Vaal River catchment comprises the most important tributary of the Orange River but is treated as separate WMA's. The WMA extends from the headwaters of the Caledon and Orange Rivers in the east to the confluence of the Orange and the Vaal Rivers, downstream of Vanderkloof Dam in the west. The water resources and requirements of Lesotho are determined as they affect the water resources management of the Upper Orange WMA. The Upper Orange WMA is upstream of the Lower Orange WMA. The Lower Orange WMA delivers water to Namibia.

The Caledon River forms the north-western boundary of Lesotho with South Africa and is a major tributary of the Orange River. The Caledon River joins the Orange River a short distance upstream of Gariep Dam. Upstream of this confluence the Orange River is joined by the Kraai River at Aliwal North. The main tributaries joining the Orange River downstream of Gariep Dam are the Stormberg and Seacow Rivers. These two tributaries are small in terms of water resources.

Greater Bloemfontein in the Modder River catchment is the largest urban area in this WMA. Kimberley is situated on the northern WMA boundary with the Lower Vaal WMA and is considered to be part of the Lower Vaal WMA. Other significant urban areas are Thaba Nchu, Botshabelo, Wepener, Dewetsdorp, Reddersburg, Edenburg, Jagersfontein, Trompsburg, Brandfort, Dealesville, Petrusburg, Jacobsdal, Koffiefontein, Oppermans, Fauresmith, Trompsburg, Springfontein, Bethulie, Smithfield, Rouxville, Zastron, Vanstadensrus, Barkly East, Ficksburg, Colesberg, Aliwal North and Phillipolis.

*Corresponding author: Pululu Sexton Mahasa, Department of Geography, Faculty of Natural and Agricultural Sciences, Qwaqwa Campus, University of the Free State, Private Bag X13, Phuthaditjhaba 9866, South Africa, Tel : +27 58718 5036; Fax: (+27) 58718 5055; E-mail: mahasapululusexton@gmail.com

Received August 21, 2015; Accepted October 01, 2015; Published October 07 2015

Citation: Mahasa PS, Palamuleni LG, Ruhiiga TM (2015) Uncertainties in Techniques used to Determine Areas under Irrigation in the Upper Orange River Basin. Hydrol Current Res 6: 213. doi:10.4172/2157-7587.1000213

Copyright: (c) 2015 Mahasa PS, et al. This is an open-access article distributed under the terms of the Creative Commons Attribution License, which permits unrestricted use, distribution, and reproduction in any medium, provided the original author and source are credited. 


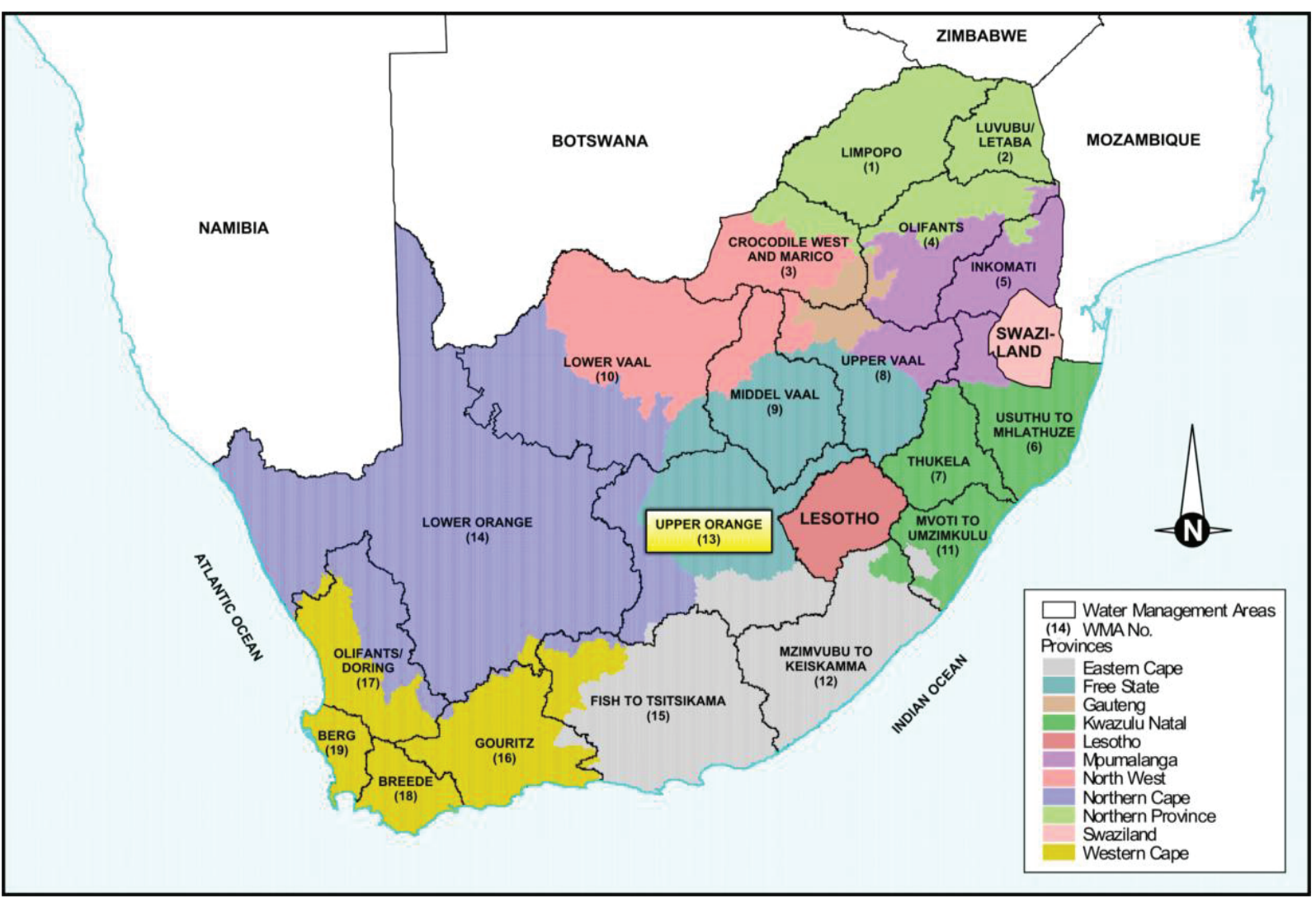

Figure 1: Location of upper orange river.

In Lesotho, the only significant urban area is the capital city, Maseru. Other significant urban areas in the area include Leribe, Mohale'shoek and Mafeteng.

Topography: The Orange River length is reported in the literature to be between 1900 to $2300 \mathrm{~km}$. However, the river length was calculated to be $2415 \mathrm{~km}$ from a detailed measurement in Google Earth and Garmin MapSource. This would place the Orange River as the 44th longest river in the world. The mountainous topography in Lesotho results in a sharp river slope with an average of about $3.9 \mathrm{~m} / \mathrm{km}$ for the first $400 \mathrm{~km}$, but from the South African boarder to Upington bridge the flat topography results in a moderate low slope of about $0.55 \mathrm{~m} / \mathrm{km}$, followed by the lower reach (Upington to river mouth) where the river drops on average with $1.04 \mathrm{~m} / \mathrm{km}$, including the Augrabies falls [2].

Geology: The geology of the study area is of volcanic origin in the upper reaches in the Lesotho Highlands characterised by young rock types of two series of the Karoo system. Extrusive igneous rocks of the Stormberg series (part of Karoo system) cover the eastern high-lying areas. The north-western part of this WMA is described as compact, dominantly argillaceous strata with small pockets of compact tillite and compact sedimentary and extrusive rocks near the WMA boundary. Compact arenaceous and argillaceous strata (fine sedimentary rocks of the Karoo system) underlie the remainder of the Upper Orange WMA.

The upper layer namely the Lesotho formation comprises of 1,500 $\mathrm{m}$ thick basalt lavas underlain by Clarens sandstone formation, Molteno beds and the upper Beaufort beds. Gradients are steep. The middle part of the area is dominated by the consolidated sedimentary rocks of the Karoo succession. The lower part of the area is under Kalahari sand cover [2]. Moving westwards, the Orange River exposes some of the oldest known rocks as it traverses many geological units in its valley (Orange-Senqu River Commission [3]. Of these geological formations, only the Kalahari sands are water-bearing in primary openings. Groundwater is available mainly in larger dissolution openings and fractures[4].

It is further mentioned that hydrogeological information for the South African part of the Orange River Basin can be obtained from Vegter.

Climate: Considerably the climatic conditions vary from east to west across the Upper Orange WMA. Excluding Lesotho, the mean annual temperature ranges between $18^{\circ} \mathrm{C}$ in the west to $12^{\circ} \mathrm{C}$ in the east and averages about $15^{\circ} \mathrm{C}$ for this area as a whole. In Lesotho, the mean annual temperature ranges from $14^{\circ} \mathrm{C}$ to below $8^{\circ} \mathrm{C}$ in the more mountainous parts towards the east with an average of about $11^{\circ} \mathrm{C}$ for the country as a whole. Maximum temperatures are experienced in January and minimum temperatures usually occur in July. Rainfall is almost all seasonal and most rain occurs in the summer period (October to April). December to March are the peak rainfall months. Rainfall occurs generally as convective thunderstorms and is sometimes accompanied by hail. The mean annual rainfall decreases fairly uniformly westwards over the Upper Orange WMA from the eastern escarpment regions across the central plateau area. Rainfall amounts are highest in Lesotho at approximately $2000 \mathrm{~mm}$ per year and decrease to about $200 \mathrm{~mm}$ in the west of the study area with a high degree of variability as well (Figure 2). The mean annual rainfall for the area is about $400 \mathrm{~mm}$ per year. This makes about $50 \%$ of the area referred to as hyper-arid to semi-arid, with an increase in aridity westwards. Due 


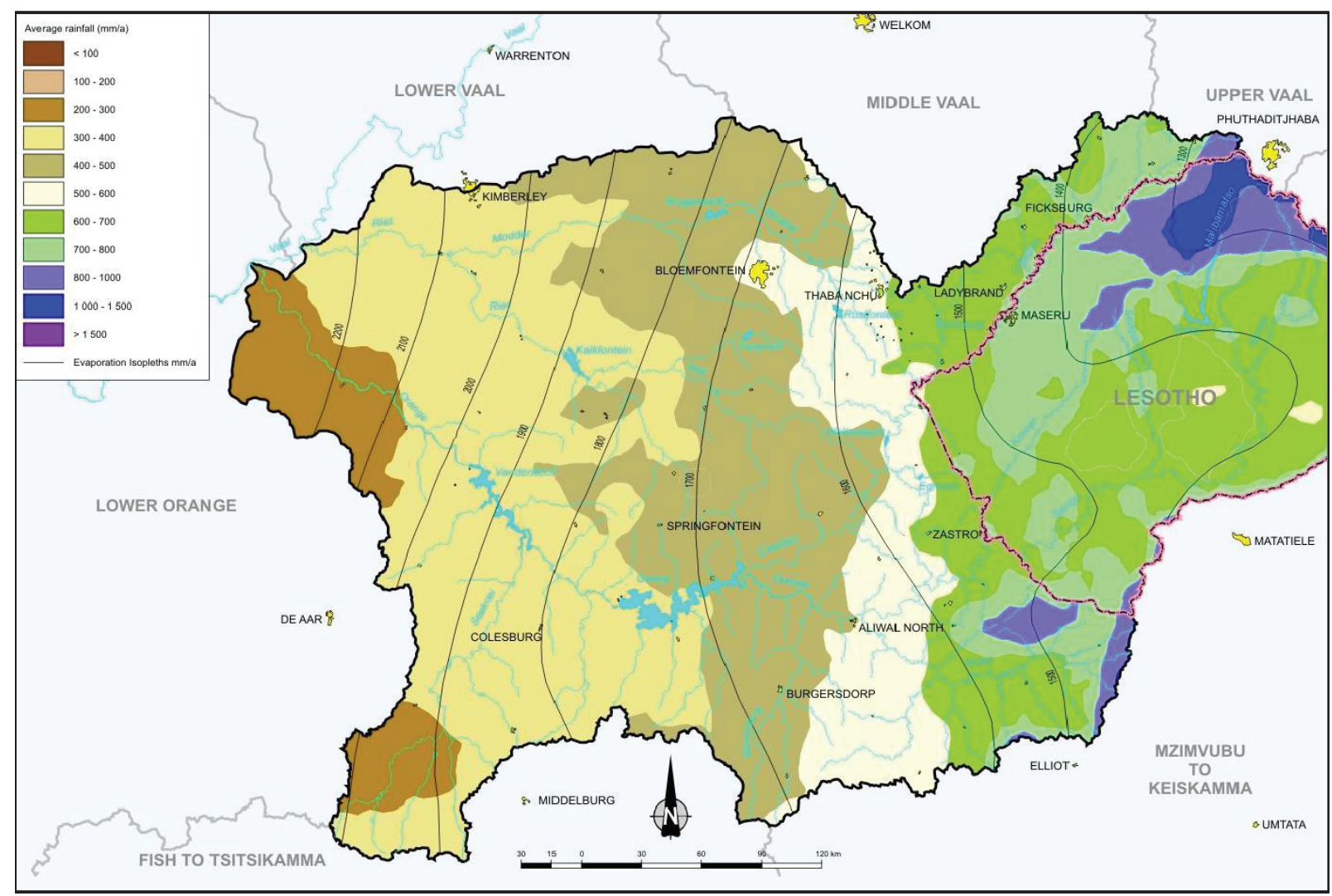

Figure 2: Distribution of annual rainfall of Upper Orange River.

to climatic variations, recorded extremes in runoff have been between 26000 million $\mathrm{m}^{3} / \mathrm{a}$ and as low as $1100 \mathrm{~m}^{3} / \mathrm{a}$ [2].

Equally variable is potential evaporation. In Lesotho, a low value of $1200 \mathrm{~mm}$ per year has been recorded to a high value of $3500 \mathrm{~mm}$ per year at the river mouth. The calculated evaporation losses from the Orange River ranged from 575 million $\mathrm{m}^{3} / \mathrm{a}$ at an annual low flow release rate of $50 \mathrm{~m}^{3} / \mathrm{s}$ to 989 million $\mathrm{m}^{3} / \mathrm{a}$ at an annual release rate of $400 \mathrm{~m}^{3} / \mathrm{s}$ [2].

Vegetation: At the highest altitudes in Lesotho, there is Alpine vegetation that comprises of climax heather communities of the pure grassveld veld type (which requires moderate to high rainfall) composed mainly of low woody species interspersed with alpine grasses. High-lying areas consist of grassland habitat while westwards to the False Upper Karoo in the remaining lower altitude; the area has the mixed sour Grassveld. The middle and lower Orange River basin are characterised by a series of karooid vegetation types [3]. According to Mucina and Rutherford [4], moving north to the Modder-Riet catchment, there is still some pure grassveld in the east but most of this catchment is false karoo and false bushveld. In the south and southwestern parts of this WMA one finds mainly false karoo together with karoo and karroid and false bushveld. There is also a bit of false karoo along its western edge where it is drier.

Soils: In Lesotho, the main Mountain Black Clays soils are dominant. At high altitudes, these are very shallow and erode easily under marginal overgrazing and cultivation practices. On the summit during summer, soils are often waterlogged and they usually freeze in winter, increasing their susceptibility to erosion [3]. Soil depths are generally moderate to deep over the upper Orange catchment. There are six main soil/texture/relief types that predominate and the section that follows indicates their distribution across the catchment:

- Sandy Loam: In the upper Caledon valley and to the south of the Orange in the western part of the catchment of moderate to deep depth and undulating relief.

- Clay Soil: Confined to the mountainous areas in the eastern portion of the Lesotho of moderate to deep depth and steep relief.

- Sandy Soil: Confined to areas around Bloemfontein and Petrusburg of moderate to deep relief and flat relief.

- Clay Loam (flat relief): Confined to the north-western part of the catchment of moderate to deep depth.

- $\quad$ Clay Loam (Steep relief): Confined to the south-eastern part of the WMA of moderate to deep depth.

- $\quad$ Clay Loam (undulating relief): The predominant soil type in the remainder of the catchment of moderate to deep depth.

Sands or weakly developed soils cover most of the remainder of the Orange River catchment area. With the exception of mainly the Kalahari component, in terms of soil erosion most of the basin is considered to be of medium to high risk [3].

Water Resources: The surface water resources, which naturally occur in the WMA (together with inflows from Lesotho), are already well developed, and with a high degree of utilization. Estimated natural water resources of the Orange River basin are about 12000 million 
$\mathrm{m}^{3} /$ annum $\left(\mathrm{Mm}^{3} / \mathrm{a}\right)$, although currently less than $50 \%$ of the available water is abstracted by several developments in the Orange and Vaal catchment areas. Approximately $4000 \mathrm{Mm}^{3} / \mathrm{a}$ of the natural runoff originates in the Lesotho Highlands, and approximately $800 \mathrm{Mm}^{3} / \mathrm{a}$ originates from another basin downstream of the Orange-Vaal Rivers' confluence. The remaining $6500 \mathrm{Mm}^{3} / \mathrm{a}$ is contributed by other areas in the basin to the Vaal, Caledon, Kraai and Middle Orange Rivers. The Vaal River is a major and very important tributary of the Orange River that provides Gauteng with all its water. According to Figure 3, extensive water resource developments have taken place upstream of this confluence, including several large dams and inter-basin transfer schemes [2]. A further classification of the study area is with regard to hydrological zones and these are the Senqu, Caledon, Riet/ Modder and Upper Orange River hydrological zones [5].

Development of the Orange River: In Southern Africa, the Orange River catchment is the most developed of all the rivers, with at least more than thirty-one major dams having a storage capacity of more than $12 \times 10^{6} \mathrm{~m}^{3}$ [6]. The Orange River (together with its main tributary the Vaal River) is controlled through storage reservoirs in the upper WMA and in Lesotho, with limited regulation capacity in the Lower Orange WMA. The main storage dams are Gariep and Vanderkloof. The construction of the Gariep and Vanderkloof Dams in the Orange River made a great contribution towards the establishment and maintenance of irrigated crops throughout large sections of the Orange River, however, with a negative impact on the environment. Largescale infrastructural development (dams, etc.) and water abstraction in the catchment result in only half of the 11500 million $\mathrm{m}^{3}$ annual runoff reaching the Orange River estuary further down of the study area in the west. Until today most of the Orange's water is used for irrigation farming, i.e. about $2160 \mathrm{Mm}^{3} / \mathrm{a}$ to irrigate approximately 180000 ha. Water is also used for the generation of hydropower at Gariep and Vanderkloof dams. As the power is essentially generated with water released for other purposes, this is not regarded as an additional requirement for water [2]. However, the unnatural regulation of flows in the river has numerous effects on the physical, chemical and biological characteristics of the Orange River.

Along the Senqu River in Lesotho, mixed farming charecterised by extensive sheep and cattle farming and wheat ploughing in the river's valley is practiced. About $70 \%$ of home gardens of these rural households produce rain-fed vegetables and household and/ or community domestic water is supplied for occasional irrigation when rains are erratic. Almost all home-grown vegetables are for consumption and small quantities are sold at village markets. In the Upper Orange-Senqu basin, the Lesotho Highlands Water Project and the associated huge investment it has impact significantly on Lesotho's political economy [7].

In South Africa in the Upper Orange River WMA the level of economic development along with population numbers are much greater than in Lesotho. Livestock farming is the main economic activity and rain-fed cultivation covers extensive areas [7].

Throughout the catchment a wide variety of crops are grown under irrigation because of the extreme range of climatic conditions of the Orange River that vary from cool temperate and alpine regions through progressively more arid terrain and ultimately through hyperarid desert. Mostly crop production is rain-fed and is interspersed with

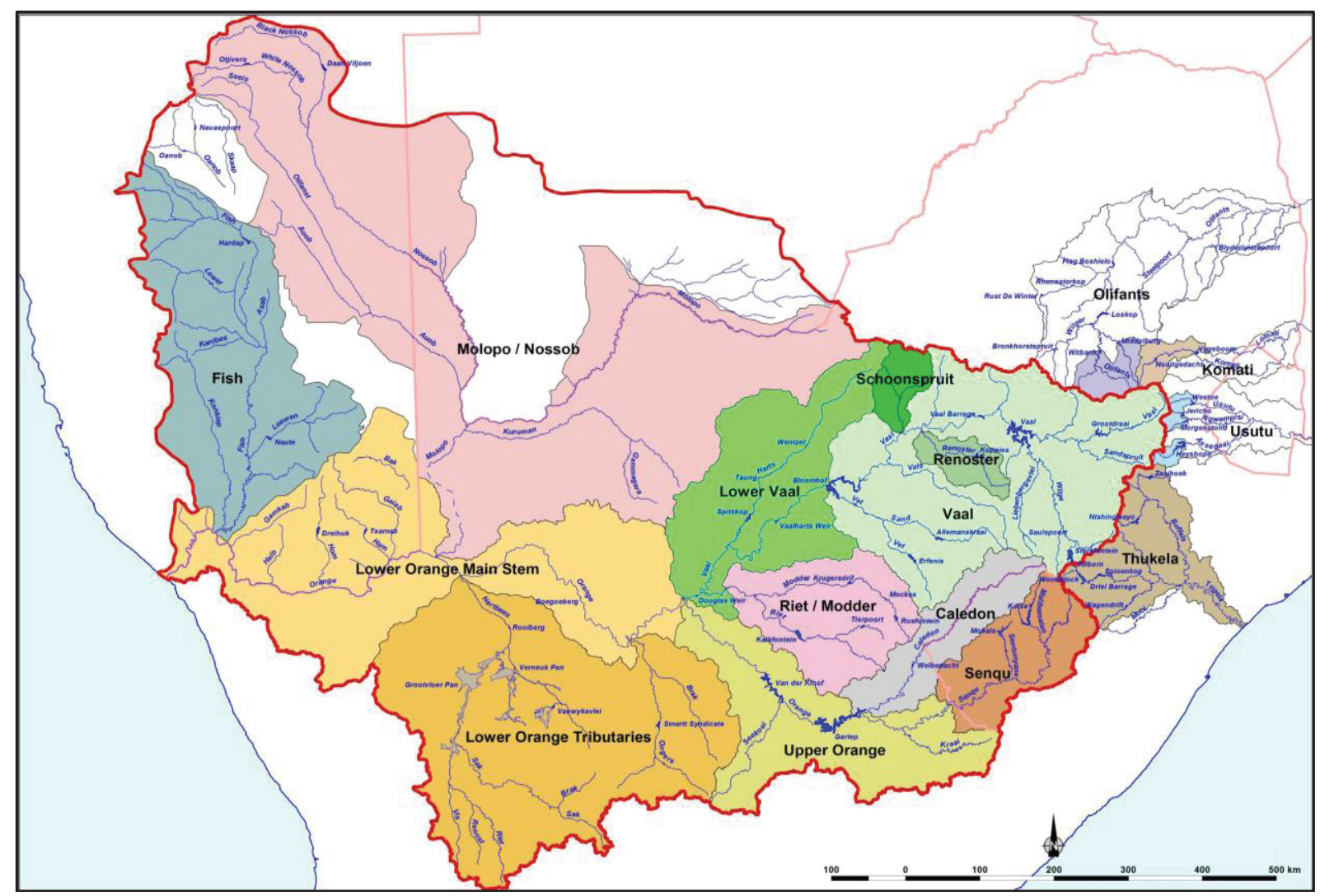

Figure 3: Orange River catchment base map and main hydrological zones. 
cropping under irrigation in the more temperate north-eastern sections of the basin. Moving westwards, irrigation supports crop production to the point where rainfall is very unreliable or very low and crops are produced only under irrigation. Predominantly in the more temperate north-western sectors there is mixed cropping with field crops and fodder crops. The main field crops are maize, wheat, dry-bean, potato, soybean, groundnut and cotton while the main fodder crops are lucerne, pastures and maize-silage. Limited areas of orchard crops such as peaches, apples and cherries are grown in the high altitude areas with adequate winter chill. Permanent orchard and vine crops like wine grapes, table grapes, raisin grapes, citrus and dates predominate in the dryer western areas also common to this area is lucerne [6].

Formerly in the Upper Orange, mining activities were a dominant sector but have declined in recent years such that small diamond operations and salt works now remain [7].

\section{Methodology}

The aim of this section is to discuss the methodology used in this study to challenge uncertainties in techniques used to determine areas under irrigation in the Upper Orange River Basin. The method made use of Remote Sensing (RS), namely LandSat imagery (Landsat 7-ETM+):

\section{Imagery:}

- Spectral Bands: Landsat TM bands (i.e., all seven),

- Datum/ Projection: Self organizing Map (SOM) / World Geodetic System 1984 (WGS84),

- Coverage Date: Scene dependent (nominally $2011+$ +/- 3 years),

- Coverage: Single Landsat WRS Path/Row,

- Pixel Size: Combination of 30 and 28.5 metres,

- Orientation: Path oriented,

- Interpolation Technique: Cubic Convolution.

Allocation schedules from Department of Water Affairs (DWA) and Orange-Senqu River Commission (ORASECOM), questionnaires and interviews and finally where possible after permission was granted field observations were also used. In order to retrieve key policy information on both external and internal issues from the two countries, four questionnaires were allocated. Each distributor was allocated one questionnaire in this tier level. In total seven water users in the study area and immediate surrounds were considered.

This research used questionnaires, interviews with specialists and key role-players and observations where possible. The questionnaire dealt with general demographic data of respondents intended to ease the mood between the researcher and the respondent as it has no bearing on the study. It further addressed policy, water allocation, financial, technical, human and material resource capacity information of the selected water institutions. In total, there were sixty questions in the questionnaire. Most questions were close-ended and respondents were guided by given options already set out. Open-ended questions allowed respondents freedom to express their views. The water users chosen for interviews were chosen on the basis of a particular status. The inclusion criteria were based on data availability, role in the local economy, etc. Choosing interviewees was on the basis of their working area and expertise in the areas of water management in their respective institutions. Only one interview was chosen per institution. It was forethought that the key respondents could confirm or correlate existing information in allocation schedules.

\section{Sampling procedure}

The sampling network and strategy was designed to cover wide range of determinant factors (i.e., water allocation needs, number of licenses issued, etc.) at the key locations, which reasonably represented the whole study area. It involved retrieving information from the national, provincial, municipal and various users' inventories in the area.

\section{Data collection}

Primary data was collected through field surveys. Allocation schedules indicating water licensing from DWA and ORASECOM were used. The use also included the $2009-10$ field crop boundaries by the Department of Agriculture, Forestry and Fisheries (DAFF) and Water Authorization and Registration Management System (WARMS) database for water use registration conducted in January 2010.

\section{Results from other studies}

Of all the Satellite Imagery available, ranging from USGS Landsat imagery (through the GLOVIS viewer), SPOT Image data, Google Earth imagery to ESAD MrSID, only Landsat 7- ETM+ for 2013 up to 2014 was considered for use. Appearances and bands used were: Spectral Bands: 3- Landsat TM bands (i.e., Band 2 (visible green light) is indicated as blue, Band 4 (near-infrared light) is indicated as green and Band 7 (mid-infrared light) is indicated as red). The main purpose was to determine irrigated areas according the current version of the field crop boundary mapping by DAFF [6]. It is further mentioned that much of the USGS archive for this dataset was downloaded to achieve this objective. However, downloading every scene available for processing was impracticable with the resources available.

\section{Selection of Satellite Imagery}

Landsat images obtained though they were freely available but the files were very large (between 200 and $300 \mathrm{Mb}$ ). Since the images were many then downloading this volume of data (i.e., 550 Gigabytes of raw and processed imagery) was eventually problematic. Other data management requirements included compressing and uncompressing from one format to the other. For example, each image had to be compressed (in GZ format) followed by uncompressing to produce a single .TAR file. A second stage of uncompressing of the .TAR file produced 9 .TIF files. Each TIF file produced a separate band width that consisted of the image. Each file had the image location_date band number format. In this analysis the six bands used were band 7 (B70), band 5 (B50), band 4 (B40), band 3 (B30), band 2 (B20) and band 1 (_B10). The other bands were inappropriate to be used for the classification of vigorously growing vegetation [6]

The decision was to use LandSat 7 with 'slcoff' to determine irrigated areas. The part of the sensor system controlling the satellite movement on the scanning process was not functional for some time during 2003, and that resulted with images that had strips up to $30 \%$ image information missing. For most tiles, a time series of scenes was possible to obtain and missing values for selected were filled because the exercise was furnished with the field crop boundaries by DAFF from 2006 to 2008 . In that project, approximately a $30 \%$ overlap existed. For each satellite image (or scene), the coverage was called a 'TILE'.

At the same "tile" location for 2009 to 2011, satellite imagery was 
made available at different times providing up to 20 scenes for each individual tile were made available, though not all of them could be utilised. That made it possible irrigated areas to be classified for the different times of the year. The exercise involved utilising at least 4 'scenes' at each "tile" location so that identification of irrigated crops growing during the different seasons could be done. This was, however, impossible due to unavailability of specific images from the USGS (images covered in cloud and images containing missing data) [6].

\section{Image Processing}

ORASECOM [6] mentioned that in order to process satellite imagery, GIS software and the IDRISI image processing was used. Only two paths (Paths 170 to 172) will be discussed and considered in the study area. These represented areas that practised irrigated rainfed and mixed agriculture, and where crop production was supported by irrigation was done due to low annual rainfall (i.e., $400 \mathrm{~mm}$ or less).

After the evaluation of several classification methods, only two of the clustering algorithms, namely the Kmeans and Cluster methods could be used. Clustering is ubiquitous in science and engineering, with diverse and numerous application domains, ranging from medicine and bioinformatics to the social sciences. It is mentioned that a "satisfactory" classification is provided by the Kmeans, but is very slow in comparison to the Cluster technique which is very fast. It should also be mentioned that the main aim was to basically determine only two classes- under irrigation or not [6].

\section{Kmeans}

Kmeans is one of the simplest unsupervised learning algorithms that solve the well-known clustering problem. The classification a given data set through a certain number of clusters (assume k clusters) fixed a priori is achieved in a simple and easy way. The determination of $\mathrm{k}$ centroids, one for each cluster is central to this procedure. These centroids are cleverly placed because of differences in location that lead to differences in the result. So, the best option is that placement should be as far away from each other as possible. For any adjacent points, a relational association for a given data set and the nearest centroid is also placed under consideration. When no point is pending, the first step is completed and an early groupage is done. At this point the re-calculation of $\mathrm{k}$ new centroids as barycentres of the clusters that resulted from the previous step is a necessity. Having acquired these $\mathrm{k}$ new centroids, a new binding should be determined between the same data set points and the nearest new centroid, thus producing a loop. As a result of this loop observations may indicate a change in location of the $\mathrm{k}$ centroids step-wise until no further changes are achieved. In other words centroids are now fixed.

Finally, this algorithm minimises an objective function (i.e., a squared error function). The objective function:

$$
\begin{aligned}
& W(C)=\frac{1}{2} \sum_{k-1}^{K} \sum_{C(i)-k} \sum_{C(j)-k}\left\|x_{i}-x_{j}\right\|^{2}=\sum_{k-1}^{K} N_{k} \sum_{C(i)-k}\left\|x_{i}-m_{k}\right\|^{2} \\
& \text { where } \\
& m_{k} \text { is the mean vector of the } k^{\text {th }} \text { cluster } \\
& N_{k} \text { is the number of observations in } k^{\text {th }} \text { cluster } \\
& \text { The algorithm comprises of the following steps: }
\end{aligned}
$$

1. Place K points into the space represented by the objects that are being clustered. These points represent initial group centroids.

2. Assign each object to the group that has the closest centroid.
3. When all objects have been assigned, recalculate the positions of the K centroids.

4. Repeat Steps 2 and 3 until the centroids no longer move. This produces a separation of the objects into groups from which the metric to be minimized can be calculated.

The Kmeans Method is classified as either a "fine" or a "broad" type. Using the classification that is "fine" created a larger number of classes (about 40) whereas the "broad" classification provided classes ranging from 10 to 16 . Smaller number of classes gave way to problems, due to combinations between larger numbers of pixels with similar signatures in the software, such that both non-irrigated and irrigated areas of healthy growing vegetation were perceived as one class. Based on this, the cluster technique was considered for use also.

\section{Cluster}

Clustering can be regarded as the most important unsupervised learning problem; so, as every other problem of this kind, it deals with finding a structure in a collection of unlabelled data. Clustering could be defined as the organisational process of grouping objects into categories whose members have similarity in some way. A cluster is therefore a collection of objects which are "similar" between them and are "dissimilar" to the objects belonging to other clusters.

There are two types of clustering: conceptual clustering and distance-based clustering.

\section{The Goals of Clustering}

The determination of the intrinsic grouping in an unlabelled data-set is the central goal of clustering. But what constitutes a good clustering is very difficult to decide? Actually there is no absolute "best" criterion which would be independent of the final aim of the clustering. Consequently, it is the user who should define and decide on this criterion, such that the result of the clustering will suit individual applications and needs.

For instance, for homogeneous categories (data reduction) there could be an interest in obtaining members so as to find "natural clusters" and describe their unknown properties ("natural" data types), in obtaining useful and suitable categories ("useful" data classes) or in obtaining unusual data objects (outlier detection).

\section{Requirements}

A clustering algorithm should:

- account for scalability;

- discover clusters with arbitrary shape;

- deal with different types of attributes;

- be able to deal with outliers and related noise;

- have minimal required conditions for domain knowledge in obtaining input parameters;

- exhibit insensitivity to the order of input records;

- show usability and interpretability.

- reflect high dimensionality;

\section{Problems}

There are numerous problems associated with clustering. Among them: current clustering fail to satisfy all the required conditions 
sufficiently (and concurrently); handling large number of data sets and large number of dimensions is often problematic due to time complexity; the effectiveness of the technique is governed by the definition of "distance" (for distance-based clustering); if a distance measure is non-existent it has to be defined and that is not easy, especially in multi-dimensional spaces; the result of the clustering algorithm (that in many cases can be arbitrary itself) can be interpreted in different ways.

\section{Classification of Clustering Algorithms}

Clustering algorithms may be categorised as below:

- $\quad$ Exclusive Clustering

- Hierarchical Clustering

- $\quad$ Overlapping Clustering

- $\quad$ Probabilistic Clustering

In the first case data are categorised exclusively, so that if a certain datum was a member of a definite cluster then it belonged there only. On the contrary the second type, the overlapping clustering, utilises fuzzy sets to cluster data, so that each point may be a member of two or more clusters with different degrees of membership. In this case, data will be associated to an appropriate membership value. Instead, a hierarchical clustering algorithm is on the basis of the union of the two nearest clusters. The initial condition is every datum is set as a cluster. The final clusters wanted may be reached after a few iterations. Finally, a completely probabilistic approach is used in the last kind of clustering.

For the study area, the cluster technique created around 60 to 100 classes and clearly separated pixels from irrigated crops and pixels that represented vigorously growing natural vegetation or rain-fed crops. This technique therefore enabled the user to select classes to a certain degree of accuracy that defined irrigated crops only (ORASECOM )[6]. While most practitioners instead continue to use a variety of heuristics that have no known performance guarantees.

\section{Selection of the Best Method}

ORASECOM [6] Mentioned that the three techniques (clusters fine and broad, kmeans) in comparison to the Standard False Colour Composite (FCC) may first select the best method. Secondly, identification of the classes showing irrigated areas would be done. This categorised the classified images with the FCC image so as to enable the user to "zoom in" on the same field on all the images and do the comparison. In IDRISI when using the MAP COMPOSER facility to overlay the field crop boundary vector layer, this exercise could be achieved easily.

\section{Identification and selection of the correct class}

By zooming in to different locations across the image the user was able to select the classes that best represent irrigation. As mentioned in the previous section, some classes from the clusters classification were chosen to best represent irrigated crops in that tile [6].

These selected classes were then retained, and all other classes ignored, to create a new image that illustrated vigorously growing/ irrigated crops only. Classes would now be shown in the same colour: red. The FCC is included for comparison purposes. This new image, showing vigorously growing/irrigated crops, would be placed in all the tile folders, where image under process was undertaken and represented the last step using the IDRISI software. It should be recalled that a large number of files were placed in some of the tile folders. This was due to methodology investigated before the current technique was adopted [6].

Finding the most effective classification method was preceded by a great deal of experimentation. These included a method initially explored where the image was firstly divided into four quadrants, then masked with the field crop boundaries, before interpolating to fill in missing data.

\section{ArcGIS}

The rasterised file indicating pixels categorised as irrigated/ vigorously growing crops was imported to the ArcMAP module in ArcGIS. An attribute table was made where all classified irrigated areas was labelled " 1 " and all non-irrigated areas was assigned a " 0 " and overplayed with the field crop boundary in a process that determined the area of irrigated/vigorously growing crops in each field crop boundary. ORASECOM [6] indicated that this process involved the following steps:

- Convert the field crop boundary from a vector shapefile to a rasterised file. This speeds up the combining of the field crop boundaries and classified rasterised images.

- The Tabulate Area function in the Zonal option under Spatial Analyst Tools in ArcToolbox was used to create an attribute table that contains the area of vigorously growing/irrigated crops in each field crop boundary.

- This attribute table was exported as a DBASE ('.dbf) table.

\section{Classification Process}

The classified image clearly showed how the classification process often resulted in varying proportions of each field being classified as vigorously growing. The centre pivot would show approximately $70 \%$ classified as vigorously growing, while the centre pivot top centre indicated slightly less than $10 \%$ vigorously growing. The '.dbf' file that defines each field with a unique ID also lists the actual area of vigorously growing vegetation (value_1) and non-vigorously growing vegetation (value_0) in each field.

\section{Strict classification versus less strict classification}

It is mentioned in ORASECOM [6] that during the class selection process, classification was based on a variable percentage of cover to say if a particular field was irrigated or not. To the east of the Vaal basin, the crops were often grown during the rainy summer months, so only complementary irrigation and sometimes no irrigation was required. The exercise to separate the rain fed crops from those that are irrigated had to use a very strict classification. A low percentage of $30 \%$ was used if the classification of a particular image was strict (i.e., only the most vigorously growing vegetation identified). This meant that a field was identified as being under irrigation if $30 \%$ or more of the field was classified as irrigated. If the classification was less strict, then a higher cut off percentage of (say 70\%) was utilised.

\section{Selection of images and variability within images}

Summer images which were inclusive of immense areas of rain-fed crops were rejected. An iterative process was in under consideration on the effect of including/excluding summer images, where the user was able to rapidly assess the results and necessitate a database type analysis. In addition, it was necessary to identify and anticipate that fields near rivers and/or within formal irrigation boards are more likely to be irrigated. Across a single image, different criteria were therefore 
Citation: Mahasa PS, Palamuleni LG, Ruhiiga TM (2015) Uncertainties in Techniques used to Determine Areas under Irrigation in the Upper Orange River Basin. Hydrol Current Res 6: 213. doi:10.4172/2157-7587.1000213

Page 8 of 10

applied. Again, based on the best achievement it was better to use a buffer system embedded in an ACCESS database that undertook the classification of the fields within these buffers more reliably than those outside the buffer [6].

\section{Interactive classification tool}

According to ORASECOM [6], it became apparent that in order for above-mentioned requirements to be achieved, a tool was necessary to enable all that could be done. An Access database with an interactive tool, which allowed a user to determine the effects of remote sensing classification thresholds to distinguish between vigorously growing vegetation and irrigated crops, and location-based screening rules which acknowledge:

- Run-of-river abstractions along major tributaries; and known groundwater abstraction areas;

- Irrigation schemes.

It is further mentioned that the tool could simplify future updating of estimates of irrigation areas as it encapsulates the methodology described above, validates other data sources (such as the WARMS), and to make use of local knowledge about sources of irrigation water.

The steps used in this tool as mentioned in ORASECOM [6] are as follows:

- For each image, importing the '.dbf file;
- Defining the cut-off percentage. The database calculated the percentage coverage of vigorously growing vegetation for each field, in comparison to the cut-off percentage of that image scene to determine if a field was irrigated or not;

- Considering as "irrigated", all fields under centre pivots as per DAFF field crop boundary data;

- Incorporating the buffer areas that had different decision criteria placed on them. Retaining all fields including those under centre pivots as irrigated when determined by remote sensing methods and defining all other fields not within the buffers as "not irrigated"; and

- Comparing the total area under irrigation per irrigation zone with other sources of information such as the WARMS database and the reports on the Orange River (the Orange River Development Project, Evaluation of Irrigation water use) and Vaal River (the Vaal River Basin Study, Evaluation of Irrigation).

It was of interest to note that the area of centre pivots differed drastically from the data sources (in Figure 4 for example 4 V6, 45.665 $\mathrm{km}^{2}$ is irrigated by centre pivots compared to $12.513 \mathrm{~km}^{2}$ of irrigated area in WARMS).

\section{Challenges and Recommendations}

$>$ Regulation of the water of the Orange-Senqu system is done

\begin{tabular}{|c|c|c|c|c|c|c|c|c|c|c|}
\hline \multicolumn{11}{|c|}{ 6-Compare Areas by Zones } \\
\hline 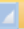 & ZONEID & - COUNTRY & OSZONE & Description & + Scheduled Area & WARMS Area & Centre Pivot Ar. & OV Study An. & RS Area & Screened Area \\
\hline & & 11 Lesotho & 01 & Caledon U/S Welbedacht Dam & & & 149 & & 106 & 174 \\
\hline & & 12 RSA & 015 & Orange-Vaal confluence to Boegoeberg Dam & 6853 & 16067 & 12592 & 6852 & 11422 & 15576 \\
\hline & & 13 RSA & 016 & Boegoeberg Dam to Upington & 8623 & 1159 & 669 & 8578 & 9807 & 9807 \\
\hline & & 14 ASA & 017 & Upington to Neusberg & 13163 & 13723 & & 13163 & 11536 & 11536 \\
\hline & & 15 RSA & 018 & Neusberg to Namibia border & 9731 & 651 & & 9731 & 9217 & 9217 \\
\hline & & 16 RSA & 019 & Namibia border to Onseepkans & 1045 & 1535 & & 1045 & 913 & 913 \\
\hline & & 40 Namibia & 019 & Namibia border to Onseepkans & & & & & 273 & 273 \\
\hline & & 36 RSA & 02 & U/s Garlep, $D / 5$ Welbedacht Dam & 4775 & 3280 & 2239 & 3482 & 1359 & 2979 \\
\hline & & 18 RSA & 020 & Onseepkans to Vioolsdrift & 835 & 1938 & & 351 & 2481 & 1887 \\
\hline & & 45 Namibia & 020 & Onseepkans to Vioolsdrift & & & & & 317 & 317 \\
\hline & & 42 Namibia & 021 & Vioolsdrift to Orange-Fish confluence & 442 & & & 210 & 2240 & 2240 \\
\hline & & 43 FSA & 021 & Vioolsdrift to Orange-Fish confluence & 442 & 316 & & 210 & 324 & 324 \\
\hline & & 41 Namibla & 022 & Orange-Fish confluence to river mouth & & & & & 181 & 181 \\
\hline & & 19 RSA & 022 & Orange-Fish confluence to river mouth & 761 & 531 & 198 & 750 & 198 & 198 \\
\hline & & 20 RSA & 03 & $\mathrm{U} / \mathrm{S}$ Alival North, $\mathrm{D} / \mathrm{S}$ Oranjedraal & 1575 & 553 & 186 & 1550 & 134 & 263 \\
\hline & & 17 RSA & 04 & U/S Gariep, D/S Aliwal North & 2560 & 2970 & 911 & 1940 & 854 & 1465 \\
\hline & & 21 FSA & 05 & Kraai U/S Aliwal North & -999 & 970 & 450 & .999 & 498 & 699 \\
\hline & & 22 RSA & 06 & $\mathrm{U} / \mathrm{s}$ Van der Kloof, $\mathrm{D} / \mathrm{s}$ Garlep & 2316 & 2418 & 1997 & 2316 & 1349 & 2345 \\
\hline & & 23 ASA & 07 & Canals ex Van der Kloof Dam & 17378 & 322 & 4420 & 17378 & 3454 & 4474 \\
\hline & & 24 RSA & 09 & Van der Kloof Dam to Douglas & 14174 & 19372 & 22004 & 14173 & 17616 & 23011 \\
\hline & & 57 RSA & oLU & Lower Orange D/s Onseepkans & & 48 & & & 2345 & 293 \\
\hline & & 44 Namibia & OLU & Lower Orange D/S Onseepkans & & & & & 392 & 6 \\
\hline & & 46 FSA & OML & Middle Orange - D/S Boegoeberg & & 16841 & 9 & & 218 & 218 \\
\hline & & 54 RSA & OMU & Middle Orange - U/S Boegoeberg & & 1379 & & & 239 & 239 \\
\hline & & 52 ASA & OUL & Orange tributaries - Van der Kloof to Douglas & & 311 & 889 & & 891 & 889 \\
\hline & & 999 Outside & OUTOFBASIN & Out of Basin & & & & & 32 & 0 \\
\hline & & 53 RSA & ouv & Orange tributarles $\mathrm{U} / \mathrm{5}$ Van der Kloof & & 11778 & 1080 & & 14484 & 3966 \\
\hline & & 6 RSA & SER & Senqu (RSA) & & 509 & 24 & & 993 & 52 \\
\hline & & 25 RSA & SH & Sak River & & 16451 & & & 16071 & 11758 \\
\hline & & 26 RSA & $v_{1}$ & U/5 Grootdraal Dam to Vaal Dam & 7279 & 20674 & 14899 & 7279 & 7667 & 15202 \\
\hline & & 27 FSA & v10 & Vaal and Riet U/S of confluence with Orange & 20869 & 10755 & 25491 & 20896 & 7270 & 29595 \\
\hline & & 28 RSA & v2 & Wilge, Liebenbergsvlei Rivers & 5517 & 24006 & 15262 & 5517 & 9229 & 16232 \\
\hline & & 29 RSA & V3 & Vaal Dam to Barrage & 9008 & 14150 & 8640 & 9008 & 8679 & 15671 \\
\hline & & 30 RSA & v4 & Barrage to Bloemhof Dam & 16586 & 43120 & 28585 & 15646 & 21818 & 33981 \\
\hline & & 31 RSA & v5 & Sand and Vet Rivers & 12196 & 15463 & 21301 & 12196 & 19289 & 23199 \\
\hline & & 32 ASA & V6 & Bloemhof Dam to Schmidtsdrift & 50277 & 12513 & 45665 & 47392 & 17540 & 69523 \\
\hline & & 33 RSA & v7 & Harts River & 1783 & 16526 & 18120 & 1763 & 6073 & 20406 \\
\hline & & 34 RSA & v8 & Rlet RIver & 4234 & 6793 & 4714 & 8391 & 1737 & 5303 \\
\hline & & 35 RSA & vg & Modder River & 3564 & 22824 & 22527 & 6371 & 9770 & 27470 \\
\hline
\end{tabular}

Figure 4: Comparisons of Irrigated Areas per Irrigation Zone. 
by more than thirty-one major dams and is also a highly complex and integrated water resource system with numerous large inter and intrabasin transfers [6].

$>\quad$ This makes the basin to be notably much interconnected" [8].

$>$ An incomplete inventory of Water Users in the Upper Orange River Basin arises as result of the vast nature of the basin.

$>$ Most irrigated land is privately owned and as such access is highly problematic.

$>$ The sensitive nature of the research makes accessibility even restricted because results could largely influence the allocation schedules of irrigation water.

$>\quad$ Until so far there is no established standard methodology for the collection of data on irrigation water applied to crops, water use by crops and crop yields.

$>$ There is also a diverse array of instruments used to support water conservation/water demand management. incentives.

Divulging correct ground information could be rewarded by

Figure 5 summarises findings of different studies undertaken to determine irrigation demand for the study area. All these studies used different methods and came up with different results in many cases. The studies were conducted by WRP Consulting Engineers (WRP), Development of Reconciliation Strategies for Large Bulk Water Supply Systems: Orange River-Irrigation Demands and Water Conservation / Water Demand Management (Task 8) (ORECON), Orange-Senqu River Commission (ORASECOM) and Orange River Re-planning Study (ORRS). It is worth-noting how results from different vary in this region. The Government of the Kingdom of Lesotho's publication of June 2012: "First Annual State of Water Resources Report (April 01, 2010 - March 31, 2011)" was consulted to provide the irrigation assumed for Lesotho [9].

The words 'equipped for irrigation' and 'believed to be irrigated' were used because, when using remote sensing techniques, it was not all that easy to be absolutely sure that an area is 'equipped for irrigation', and/or it is being irrigated, and, as proposed by consultants, an approach based on evidence was considered; with the possibility of combination from the from the multi-temporal imagery evidence with other evidence, such as: the issuance of WARMS registrations (these are point locations); the shape of the field crop boundary; mean annual rainfall; proximity to water sources (rivers, farm dams); land slope; and expert knowledge of the agricultural areas under irrigation as per team members. The satellite imagery underwent automatic classification first because, without extensive ground truth, there would be difficulty in distinguishing between land parcels as being non-irrigated, partially irrigated and irrigated, irrespective of using multi-temporal imagery. In this case additional evidence was considered in order to assist with separating out confusing classifications [6].

\section{Testing of Crop Classification Techniques}

When ground truth data on crops at a high resolution is available, it may lead to more accurate, or even useful, crop classification. This information was to large extent not available in the catchment area but progress was made using other classification techniques in selected parts of the catchment area [6].

The registered area is 13,620 ha in tile 174-82; the field crop boundary by DAFF identified 21,293 ha; based on RS selection method 6,453 ha was identified. For July 2009 the RS using filled 'slcoff' gave 4,122 ha. (i.e., disregarding 400 ha which was doubted irrigated).

According to ORASECOM [6], identification of these areas was very inconsistent so was the definition of what was considered "apparently set up for irrigation" or "irrigated". Speculations showed that while registration of a large area was done, the rainfall-runoff supplying any of the irrigated areas may be unreliable, giving rise to differences in the extent and location of actual irrigation from year to year.

\section{Ground truthing}

The use of remote sensing facilitates improvement on estimating the extent of irrigation areas in the catchment area but ground truthing may not be underestimated. It provides estimates of irrigated areas accurately even for rainfed agriculture. Ground truthing is even more useful for crop classification purposes. An emphasis in the report on the Promotion of Water Conservation and Water Demand Management in the Irrigation Sector is placed in collecting and collating of information on irrigated areas including crop types and that this should be done at the water user association level in the South African context, and

\begin{tabular}{|c|c|c|c|c|c|c|c|c|c|c|c|c|c|c|c|c|c|c|}
\hline \multirow{3}{*}{ 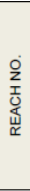 } & \multirow{3}{*}{ DESCRIPTION OF REACH } & \multirow{3}{*}{ 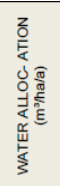 } & \multicolumn{8}{|c|}{ FIELDIRRIGATION REQUIREMENT (mill. M/la) } & \multicolumn{8}{|c|}{ IRRIGATED AREAS (ha) } \\
\hline & & & \multirow[b]{2}{*}{ 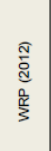 } & \multirow{2}{*}{ 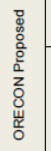 } & \multicolumn{2}{|c|}{ ORRS } & \multicolumn{3}{|c|}{ ORASECOM } & \multirow{2}{*}{$\begin{array}{l}z \\
0 \\
0 \\
\frac{2}{a} \\
3 \\
\frac{5}{3} \\
3\end{array}$} & \multirow{2}{*}{ 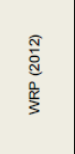 } & \multirow{2}{*}{ 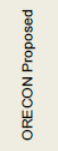 } & \multicolumn{2}{|c|}{ ORRS } & \multicolumn{3}{|c|}{ ORASECOM } & \multirow{2}{*}{$\begin{array}{l}z \\
0 \\
0 \\
z \\
0 \\
\vdots \\
\vdots \\
\vdots\end{array}$} \\
\hline & & & & & Sched. & Act & 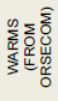 & 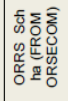 & 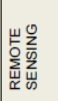 & & & & Scheduled & Act & 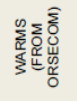 & 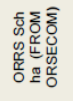 & 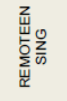 & \\
\hline 1 & Caledon River: U/S Welbedacht Dam & 7620 & 71.4 & 40.3 & 11.0 & 28.1 & 65.1 & 11.0 & 25.6 & & 9364.8 & 9930 & 1440.0 & 3692.0 & 8541.2 & 1440.0 & 3358.6 & \\
\hline 2 & Caledon River. Welbedacht Dam to Gariep Dam & 8000 & 18.2 & 36.5 & 38.2 & 27.9 & 49.1 & 26.2 & 25.6 & & 2275.0 & 5835 & 4775.1 & 3482.0 & 6142.6 & 3280.4 & 3199.3 & \\
\hline 3 & U/S Aliwal North D/S Oranjedraai & 8000 & 12.6 & 6.6 & 1.9 & 1.9 & 8.5 & 12.6 & 2.5 & & 1575.0 & 877 & 1574.6 & 1550.0 & 1061.6 & 1575.0 & 314.4 & \\
\hline 4 & Aliwal N to Gariep Dam & 8000 & 43.3 & 52.5 & 20.5 & 15.5 & 23.8 & 20.5 & 11.7 & & 2562.5 & 8229 & 2559.7 & 1940.0 & 2970.4 & 2560.0 & 1465.5 & \\
\hline 5 & Kraai U/S Alwal N & 7620 & 11.6 & 28.0 & 0.0 & 0.0 & 7.4 & 7.6 & 5.3 & & 1524.9 & 6341 & 0.0 & 0.0 & 969.5 & 999.0 & 699.1 & \\
\hline 6 & Gariep dam to Vanderkloof dam & 11000 & 28.4 & 27.7 & 25.5 & 25.5 & 26.6 & 26.0 & 25.8 & & 2580.9 & 3121 & 2316.0 & 2316.0 & 2418.3 & 2361.0 & 2345.2 & \\
\hline 7 & Canals ex Vanderkloof dam & 11000 & 201.7 & 195.1 & 191.0 & 191.0 & 3.5 & 191.2 & 49.2 & & 20914.9 & 17678 & 17377.8 & 17378.0 & 322.1 & 17378.0 & 4474.4 & \\
\hline 8 & Scholzburg and Lower Riet IBs & 9140 & 49.4 & 50.2 & 41.8 & 41.8 & 0.0 & 0.0 & 0.0 & & 5408.1 & 4564 & 4574.2 & 4575.0 & 0.0 & 0.0 & 0.0 & \\
\hline 9 & Vanderkloof Dam to Orange-Vaal conf: & $\begin{array}{l}10000 \\
t 011000\end{array}$ & 170.0 & 187.4 & 149.8 & 149.8 & 334.0 & 155.9 & 301.7 & & 15845.8 & 17455 & 14174.1 & 14173.0 & 31461.5 & 14174.0 & 27865.3 & \\
\hline 10 & Krugerdrift dam to Tweerivier gauge - Modder River & 8640 & 29.4 & $52.5^{*}$ & 29.1 & 28.9 & 197.2 & 30.8 & 237.3 & & 3402.8 & 7004 & 3364.4 & 3340.0 & 22823.5 & 3564.0 & 27470.1 & \\
\hline 11 & Tierpoort Dam to Kalkfontein Dam: Tierpoort IB & 9000 & 6.4 & $8.1^{*}$ & 6.4 & 6.0 & 0.0 & 0.0 & 0.0 & & 711.1 & 1018 & 708.0 & 665.0 & 0.0 & 0.0 & 0.0 & \\
\hline 12 & $\begin{array}{l}\text { Kalkfontein Dam to Riet River Settlement: Kalkfontein WUA } \\
\text { (canal) }\end{array}$ & 11000 & 33.5 & $56.7^{*}$ & 33.5 & 33.5 & 74.7 & 46.6 & 58.3 & & 3510.0 & 6187 & 3046.3 & 3046.0 & 6792.6 & 4234.0 & 5303.2 & \\
\hline 14 & Douglas weir to Orange-Vaal Conf. (Orange water) & 9140 & 104.3 & 104.3 & 74.2 & 66.6 & 98.3 & 190.7 & 270.5 & & 11410.3 & 11410 & 8113.0 & 7285.0 & 10755.0 & 20869.0 & 29594.7 & \\
\hline
\end{tabular}

Figure 5: Summary of Findings of Different Studies Undertaken to Determine Irrigation Demand for the Study Area. 
Citation: Mahasa PS, Palamuleni LG, Ruhiiga TM (2015) Uncertainties in Techniques used to Determine Areas under Irrigation in the Upper Orange River Basin. Hydrol Current Res 6: 213. doi:10.4172/2157-7587.1000213

Page 10 of 10

by similar status organisations in the other states. These organisations require this information and usually have a close relationship with farmers in their respective settings [6]. Funding for GIS development and training purposes for these organisations may lead to improved estimation of areas under irrigation, cropping patterns and methods of irrigation used.

\section{Updates of the database of irrigated areas}

The field crop boundaries in South Africa could be supplemented with long-term continuous mapping of areas under irrigation in Botswana, Lesotho and Namibia at the catchment level on an annual basis (ORASECOM, 2011). It further indicated that at present, isolated areas in the basin are under crop type mapping, and an expansion is being planned and could be underway soon for the whole catchment. Also under consideration is to have ground truth data from a sample of locations within each satellite image tile. The project may also need to include non-irrigated field crop boundaries. A continuous time series of satellite images is considered a vital requirement to this exercise as well. If all these could be achieved then a large improvement on confidence and estimates of irrigation water use could be determined at a relatively low cost [6].

\section{Water use monitoring system}

The potential improvement of irrigation water schedules and water use efficiency can be enhanced by developing a monitoring system for crop water use based on ground based meteorological observations and on near real-time satellite. This coupling could lead continuous mapping of crop cover, a further requirement for mapping crop types. In following on this, the data on climate parameters derived for the statistical downscaling purposes may be utilised for calibrating the development and approach of an operational system. This may serve as platform for an agricultural extension system to farmers under use in different states in the basin or governments' advisory contractors [6].

The Irrigation Scenario Tool produced according to ORASECOM [6] can undergo improvement to include:

- Industrial and domestic demands;
- Introduction of risk based scenario generation;

- The introduction of optimisation based on economic returns; and

- Coupling the Irrigation Scenario Tool (for providing estimates on irrigation water required) to the Water Resources Yield Model.

\section{References}

1. DWA-Department of Water Affairs, South Africa (2012) Reconciliation Strategy Report for the Large Bulk Water Supply Systems of the Greater Bloemfontein Area. Prepared by Aurecon in association with GHT Consulting Scientists and ILISO Consulting as part of the Water Reconciliation Strategy Study for the Large Bulk Water Supply Systems: Greater Bloemfontein Area.

2. DWAF-Department of Water Affairs and Forestry, South Africa (2009) Directorate Water Resource Planning Systems: Water Quality Planning. Orange River: Assessment of water quality data requirements for planning purposes. Water Quality Monitoring and Status Quo Assessment.

3. ORASECOM-h Orange-Senqu River Commission (2008) Preliminary Transboundary Diagnostic Analysis.

4. Mucina L, Rutherford MC (2011) The Vegetation of South Africa, Lesotho and Swaziland. Strelitzia 19. South African National Biodiversity Institute, Pretoria.

5. DWA-Department of Water Affairs, South Africa (2012) Development of Reconciliation Strategies for Large Bulk Water Supply Systems Orange River: Surface Water Hydrology and System Analysis Report. WRP Consulting Engineers Aurecon, Golder Associates Africa, and Zitholele Consulting.

6. ORASECOM-Orange-Senqu River Commission. 2011. The Promotion of WC WDM in the Irrigation Sector Report 011/2011.

7. Huggins G, Rydgren B, Lappeman G (2010) The Assessment of Goods and Services in the Orange River Basin. Produced for WRP as part of Support to Phase II ORASECOM Basin Wide Integrated Water Resources Management Plan. Report-WP-WP5-010-2010-fd.

8. DEA-Department of Environmental Affairs, South Africa (2013) Long- Term Adaptation Scenarios Flagship Research Programme (LTAS) for South Africa. Climate Change Implications for Water Sector in South Africa. Pretoria. South Africa.

9. DWA-Department of Water Affairs, South Africa. 2013. Development of Reconciliation Strategies for Large Bulk Water Supply Systems: Irrigation Demands and Water Conservation/ Water Demand Management. Pretoria WRP Consulting Engineers (Pty) Ltd., Aurecon, Golder Associates Africa, and Zitholele Consulting. 